\title{
TRIỂN VỌNG HỘI NHẬP QUỐC TẾ VỀ KHOA HỌC XÃ HỘI TẠI VIỆT NAM: PHÂN TÍCH TƯ DŨ̉ LIỆU NETWORK OF VIETNAMESE SOCIAL SCIENCES 2008-2018
}

\author{
Phạm Hùng Hiệp - Trường Đại học Phú Xuân
}

\begin{abstract}
Ngày nhận bài: 25/4/2019; ngày chỉnh sủa: 24/6/2019; ngày duyệt đăng: 25/6/2019.
Abstract: International integration is a mandatory requirement and a dispensible trend for Vietnamese science today. Specifically, when comparing between natural sciences and technology (NS-T) with social sciences (SS), many researchers suggested that SS in Vietnam have a lower level of integration than NS-T. However, according to our understanding, there have not been many statistical studies, estimates and quantitative evaluation of the integration level of Vietnam social science. In this article, using the Network of Vietnamese Social Sciences database developed by AI Social Data Lab, we introduce and analyze research results of domestic and overseas Vietnamese authors within the 2008-2018 period based on the following aspects: individual researchers (gender, study major, cooperation, leadership role), research group, work agency, study major, localities... Based on these preliminary results, a number of recommendations and policy implications would be proposed for policy makers as well as university leaders/managers.
\end{abstract}

Keywords: Social science, international integration, research outputs.

\section{Mở đầu}

Hội nhập quốc tế là yêu cầu bắt buộc và xu thế không thể thay đổi đối với khoa học Việt Nam hiện nay. Thực tiễn hoạt động khoa học trong khoảng 10 năm trở lại đây ghi nhận nhiều nỗ lực, sáng kiến của cả Chính phủ cũng như các cơ sở nghiên cứu và giáo dục đại học $(\mathrm{H})$ trong việc cố gắng đẩy nhanh mức độ hội nhập quốc tế trong nghiên cứu khoa học $(\mathrm{NCKH})$. Một điểm tương đối tương đồng giữa các nỗ lực, sáng kiến này là việc áp dụng (bắt buộc hoặc khuyến khích) các chỉ mục (index) tạp chí quốc tế như ISI Clavirate Web of Science (SCIE, SSCI, AHCI, ESCI) hay Scopus làm căn cứ để đánh giá (xem bảng 1 ).

Bảng 1. Một số nỗ lưc/chinh sách của Việt Nam để hội nhập quốc tế trong khoa học thông qua việc áp dụng chỉ mục quốc tế để làm căn cú đánh giá

\begin{tabular}{|c|c|c|c|}
\hline STT & $\begin{array}{l}\text { Tên nỗ lực/ } \\
\text { chính sách }\end{array}$ & $\begin{array}{c}\text { Cấp } \\
\text { thực hiện }\end{array}$ & Mô tả ngắn gọn \\
\hline 1 & $\begin{array}{l}\text { Thành lập } \text { Quỹ } \\
\text { NAFOSTED và } \\
\text { các quy định về } \\
\text { quản lí Quỹ }\end{array}$ & Chính phủ & $\begin{array}{l}\text { Sử dụng các chỉ mục quốc tế như ISI, Scopus làm căn cứ quan trọng } \\
\text { nhất đề nghiệm thu đề tài [1]. }\end{array}$ \\
\hline 2 & $\begin{array}{l}\text { Quy chế tuyển sinh } \\
\text { và đào tạo tiến sĩ } \\
\text { (08/2017/TT- } \\
\text { BGDĐT) }\end{array}$ & Chính phủ & $\begin{array}{l}\text { Yêu cầu giảng viên hướng dẫn và điều kiện tốt nghiệp của nghiên } \\
\text { cứu sinh phải có công trình công bố trên tạp chí thuộc danh mục } \\
\text { ISI/Scopus hoặc các ân phẩm quốc tế có phản biện [2]. }\end{array}$ \\
\hline 3 & $\begin{array}{l}\text { Thưởng bài báo } \\
\text { khoa học }\end{array}$ & $\begin{array}{l}\text { Cơ sở giáo } \\
\text { dục ĐH hoặc } \\
\text { khoa học }\end{array}$ & $\begin{array}{l}\text { Các bài báo của giảng viên đăng trên các tạp chí thuộc chỉ mục ISI, } \\
\text { Scopus sẽ được thường (mức thường tuỳ theo trường và tuỳ theo } \\
\text { chất lượng bài báo). }\end{array}$ \\
\hline 4 & $\begin{array}{l}\text { Tuyển dụng } \\
\text { giảng viên }\end{array}$ & $\begin{array}{l}\text { Cơ sở giáo } \\
\text { dục ĐH hoặc } \\
\text { khoa học }\end{array}$ & $\begin{array}{l}\text { Có bài báo công bố trên các tạp chí thuộc chỉ mục ISI, Scopus là điều } \\
\text { kiện tiên quyêt. }\end{array}$ \\
\hline 5 & $\begin{array}{l}\text { Khoán chỉ tiêu về } \\
\text { số lượng công bố }\end{array}$ & $\begin{array}{l}\text { Cơ sở giáo } \\
\text { dục ĐH hoặc } \\
\text { khoa học }\end{array}$ & $\begin{array}{l}\text { Giảng viên/nhà khoa học khi kí hợp đồng được khoán chỉ tiêu về số } \\
\text { lượng, chất lượng công bố trên tạp chí thuộc danh mục ISI, Scopus } \\
\text { (mức lương thương lượng). Nếu giảng viên/nhà khoa học có số } \\
\text { lượng/chất lượng vượt so với chỉ tiêu thì sẽ được thưởng thêm. }\end{array}$ \\
\hline
\end{tabular}


Khi đối sánh về mức độ hội nhập quốc tế, nhiều ý kiến cho rằng khoa học xã hội (KHXH) ở Việt Nam có mức độ hội nhập thấp hơn so với khoa học tự nhiên, công nghệ. Mặc dù vậy, theo nhận thức của chúng tôi, vẫn chưa có nhiều nghiên cứu thống kê, ước lượng và đánh giá một cách định lượng mức độ hội nhập của KHXH Việt Nam.

Trong bài viết này, sử dụng nguồn dữ liệu Network of Vietnamese Social Sciences (NVSS), chúng tôi giới thiệu và phân tích một số kết quả nghiên cứu của các tác giả người Việt trong và ngoài nước trong giai đoạn 2008 -2018, nhằm góp phần trả lời "khoảng trống" nghiên cứu kể trên. Cụ thể, chúng tôi sẽ giới thiệu về nguồn dữ liệu NVSS, mục tiêu, quá trình hình thành và cấu trúc của nó. Tiếp đó, dựa vào dữ liệu NVSS, chúng tôi giới thiệu và phân tích, thảo luận một số kết quả nghiên cứu của các tác giả người Việt trong và ngoài nước trong giai đoạn 2008-2018 (dữ liệu 2018 mới chỉ tính đến hết tháng 11/2018) theo các khía cạnh: cá nhân nhà nghiên cứu (giới tính, ngành, hợp tác, khả năng dẫn dắt), nhóm tác giả, trường đại học, ngành, địa phương,... Căn cứ trên kết quả bước đầu này, một số khuyến nghị và gợi ý chính sách sẽ được đưa ra đối với các nhà làm chính sách cũng như lãnh đạo/quản lí ĐH tại phần cuối của bài.

\section{Nội dung nghiên cúu}

\subsection{Giới thiệu chung về NVSS}

Dũ̃ liệu NVSS do AI Social Data Lab (thuộc Văn phòng Vuong \& Associates) thực hiện và phát triển, bắt đầu từ tháng 2/2017. AI Social Data Lab bao gồm 7 nhà nghiên cứu người Việt đang làm việc các đơn vị nghiên cứu trong và ngoài nước thuộc các lĩnh vực kinh tế, xã hội học, giáo dục, quản trị và khoa học máy tính. NVSS (Mạng lưới các nhà nghiên cứu KHXH Việt Nam) là một cơ sở dữ liệu (CSDL) khoa học mở, ghi nhận kết quả đến mức độ cá nhân của nhà khoa học thuộc lĩnh vực KHXH người Việt trong và ngoài nước và các đồng tác giả người nước ngoài. NVSS hi vọng sẽ góp phần minh bạch hoá kết quả NCKH thuộc lĩnh vực KHXH, từ đó cung cấp cho các nhà hoạch định chính sách và lãnh đạo ĐH/viện nghiên cứu thông tin đầy đủ và có mức độ tin cậy cao trong các hoạt động quản lí khoa học của mình. NVSS cũng kì vọng khắc phục được các một số vấn đề đối với thông tin liên quan đến KHXH ở Việt Nam của các CSDL quốc tế sã̃n có là: + Dữ liệu lặp; + Độ trễ thời gian lớn; + Tốn kém (Vuong, La và cộng sự, 2018) [3].

Về mặt thời gian, NVSS hiện nay chỉ ghi nhận các bài báo khoa học được công bố trong danh mục Scopus từ năm 2008 trở lại đây. Danh mục Scopus dự kiến sẽ được bổ sung bằng các danh mục khác ngoài Scopus nhưng được NAFOSTED công nhận trong thời gian tới. Năm 2008 là mốc được chọn vì nó trùng với năm Quỹ NAFOSTED chính thức đi vào hoạt động. Trong tương lai, cũng có thể chúng tôi sẽ mở rộng thời gian ghi nhận dữ liệu cho khoảng 2008 trở về trước.

Các tác giả quốc tịch Việt Nam đạt 1/2 tiêu chí sau đây sẽ được ghi nhận vào CSDL của NVSS: + Có ghi cơ quan chủ quản là một đơn vị có địa chỉ tại Việt Nam; + Bài nghiên cứu về chủ đề hoặc có lấy dữ liệu từ Việt Nam (lưu ý: nếu một tác giả người Việt, giả sử có 10 bài trong đó chỉ 4 bài đạt $1 / 2$ tiêu chí kể trên thì 6 bài còn lại sẽ không được ghi nhận vào dữ liệu của NVSS).

Quy trình thu thập dữ liệu ban đầu được thực hiện hoàn toàn dựa vào nhân lực; sau một thời gian phát triển, đến tháng 12/2017, quy trình cơ bản bao gồm các bước sau đây:

- Bước 1: Thu thập dữ liệu của các nhà khoa học và kiếm tra chéo với 5 nguồn khác nhau bao gồm: (i) Website của các tạp chí tương ứng; (ii) Thông tin từ các website chính thống; (iii) Google Scholar; (iv) Dữ liệu Scimago hoặc Scopus; và (v) Các dữ liệu khác nếu cần như PubMed, ISI WoS...

- Bước 2: Nhập dữ liệu đã được kiểm tra vào hệ thống NVSS và kiểm tra chất lượng bằng hệ thống tự động nhằm đánh giá mức độ nhất quán và chính xác;

- Buoóc 3: Xác thực dữ liệu (thông qua 3 nấc admin, giám sát và người thu thập) để chính thức đưa vào dữ liệu NVSS.

Việc áp dụng và sư dụng NVSS: Trong 2 năm 20172018, NVSS đã được áp dụng và sử dụng trong nghiên cứu, đào tạo, tập huấn và tư vẩn, cụ thể:

+ Về nghiên cứu, nhóm NVSS đã công bố 7 bài báo trên các tạp chí chuyên ngành: Ho, Do, Pham và Vuong, 2017 [5]; Ho, Nguyen, Vuong, Dam, Pham và Vuong, 2017 [4]; Ho, Vuong và Vuong, 2017 [6]; Vuong, Ho, Vuong, Nguyen, Napier và Pham, 2017 [7]; Vuong, La và cộng sự, 2018 [3]; Vuong, Napier và cộng sự, 2018 [9]; và Vuong, Nguyen, Ho, Ho và Vuong, 2018 [10];

+ Về đào tạo, tập huấn, seminar: dữ liệu NVSS được sử dụng làm tài liệu đào tạo, tập huấn, seminar về NCKH và xuất bản quốc tế tại Hội đồng Lí luận Trung ương, Trường ĐH Ngoại thương, Trường ĐH Huế, Trường $Đ H$ Phú Xuân, Trường $Đ H$ Thành Tây (nay là Trường $\mathrm{H}$ Phenikaa) và trong Chương trình Research Coach in Social Sciences thuộc Trung tâm Nghiên cứu và Thực hành Giáo dục;

+ Về truyền thông: dự án NVSS đã được một số báo/tạp chí trong nước nhắc đến như: Nhân dân, Thanh niên, Tiền phong, Vietnamnet, Tia Sáng, Khoa học và Phát triển,...

2.2. Một số kết quả nghiên cứu của khoa học xã hội Việt Nam giai đoạn 2008-2018: phân tích tù̀ NVSS

\subsubsection{Dũ liệu cá nhân}

Tính từ ngày $1 / 1 / 2008$ đến hết ngày 30/11/2018 (10 năm, 11 tháng), dữ liệu NVSS đã ghi nhận có 1.070 tác giả 
Việt Nam, hợp tác với 1.344 tác giả nước ngoài, công bố 1.937 bài nghiên cứu trên các ấn phẩm quốc tế được Scopus chỉ mục (bao gồm tạp chí, sách và kỉ yếu hội nghị). Bảng 2a và $2 b$ thể hiện danh sách của 10 tác giả hàng đầu theo giới tính nam và nữ (nếu xếp chung nam và nữ trong 01 bảng thì nhà khoa học nữ xếp thứ 1 trong bảng của nữ sẽ đứng thứ 9 trong bảng của nam). Nếu chỉ tính 10 tác giả đầu tiên (cả nam và nữ) thì tổng sản lượng của 10 (tức là khoảng $1 \%$ ) người này đóng góp $21,76 \%$ tổng sản lượng của cả nước.

Bảng 2a. Top nhà khoa học nam giới người Việt theo số lương công bố giai đoạn 2008-2018

\begin{tabular}{|c|c|c|}
\hline STT & Mã kí hiệu tác giả & Số bài \\
\hline 1 & Vm.828 & 96 \\
\hline 2 & Vm.16 & 71 \\
\hline 3 & Vm.3 & 61 \\
\hline 4 & Vm.4 & 57 \\
\hline \multirow{2}{*}{5} & Vm.402 & 50 \\
\cline { 2 - 3 } & Vm.833 & 50 \\
\hline 7 & Vm.854 & 38 \\
\hline 8 & Vm.400 & 35 \\
\hline 9 & Vm.76 & 29 \\
\hline 10 & Vm.694 & 25 \\
\hline
\end{tabular}

Trong đó: Vm: Vietnamese and Male (người Việt có giới tính nam);

Vf: Vietnamese and Female (người Việt có giới tính nữ).

\subsubsection{Dũ liệu tổ chức}

Ở góc độ tổ chức, dữ liệu NVSS ghi nhận đã có 387 cơ sở nghiên cứu/giáo dục ĐH từ Việt Nam, hợp tác với 675 cơ sở nước ngoài để công bố 1937 bài nghiên cứu kể trên. Bảng 3 thống kê 10 đơn vị có số lượng dẫn đầu cả nước về sản lượng (sổ lượng công bố) trong giai đoạn 2008-2018:

Bảng 3. Top các tổ chức Việt Nam

theo số lương công bố giai đoạn 2008-2018

\begin{tabular}{|c|c|c|}
\hline STT & Mã kí hiệu đơn vị & Số bài \\
\hline 1 & PU.1 & 241 \\
\hline 2 & PU.2 & 127 \\
\hline 3 & PU.3 & 101 \\
\hline 4 & PI.4 & 98 \\
\hline 5 & PU.5 & 95 \\
\hline 6 & PU.6 & 68 \\
\hline 7 & NU.7 & 61 \\
\hline 8 & PO.8 & 58 \\
\hline 9 & NI.9 & 46 \\
\hline 10 & PU.10 & 36 \\
\hline
\end{tabular}

Trong đó: PU: Public University (cơ sở giáo dục ĐH công); PI: Public Research Institute/Center (Viện/Trung tâm NC công); NU: Non-public University (Cơ sở giáo

\subsubsection{Dũ liệu theo địa phưong}

dục ĐH ngoài công lập); NI: Non-public Institute/Center (Viện/Trung tâm nghiên cứu ngoài công lập).

Từ bảng 3 , ta thấy, nếu chỉ tính 5 tổ chức đầu tiên thì tổng sản lượng của 5 tổ chức này đóng góp 34,41\% tổng sản lượng của cả nước.

Hình 1 (trang bên) thể hiện bản đồ kết quả công bố theo số lượng theo địa phương. Hình tròn càng to thể hiện địa phương càng có nhiều công bố. Cụ thể Hà Nội, TP. Hồ Chí

Bảng 2b. Top nhà khoa học nũ giới nguoòi Việt theo số luợng công bố giai đoạn 2008-2018

\begin{tabular}{|c|c|c|}
\hline STT & Mã kí hiệu tác giả & Số bài \\
\hline 1 & Vf. 294 & 30 \\
\hline 2 & Vf.842 & 29 \\
\hline 3 & Vf.37 & 23 \\
\hline 4 & Vf.401 & 22 \\
\hline 5 & Vf.2004 & 18 \\
\hline \multirow{2}{*}{6} & Vf.146 & 17 \\
\cline { 3 - 3 } & Vf.835 & 17 \\
\cline { 2 - 3 } & Vf.910 & 17 \\
\hline \multirow{2}{*}{9} & Vf.240 & 16 \\
\cline { 3 - 3 } & Vf.204 & 16 \\
\hline
\end{tabular}

Minh là hai địa phương có nhiều công bố nhất cả nước, tiếp theo đó là Đà Nẵng, Cần Thơ, Khánh Hoà, Nha Trang.

Hình 2 (trang bên) thể hiện mức độ hợp tác của các tác giả từ Việt Nam so với các tác giả quốc tế (trong đó có bao gồm tác giả Việt Nam nhưng lại đang làm việc ở nước ngoài). Hình 3, 4 tương tự hình 2 nhưng chỉ tính cho 2 địa phương là Hà Nội và Huế.

\subsubsection{Dũ liệu theo ngành}

Tổng kết theo ngành (lĩnh vực) công bố, chúng tôi thu được kết quả như bảng 4 dưới đây:

Bảng 4. Top các ngành ở Việt Nam

theo số lương công bố giai đoạn 2008-2018

\begin{tabular}{|c|l|c|}
\hline STT & \multicolumn{1}{|c|}{ Tên ngành } & Số bài \\
\hline 1 & Kinh tế & 495 \\
\hline 2 & Chăm sóc sức khoẻ & 242 \\
\hline 3 & Giáo dục & 239 \\
\hline 4 & Kinh doanh & 215 \\
\hline 5 & Xã hội học & 152 \\
\hline 6 & Môi trường, khoa học bền vững & 133 \\
\hline 7 & Nông nghiệp & 109 \\
\hline 8 & Quản lí & 101 \\
\hline 9 & Luật & 83 \\
\hline 10 & Khoa học chính trị & 67 \\
\hline
\end{tabular}




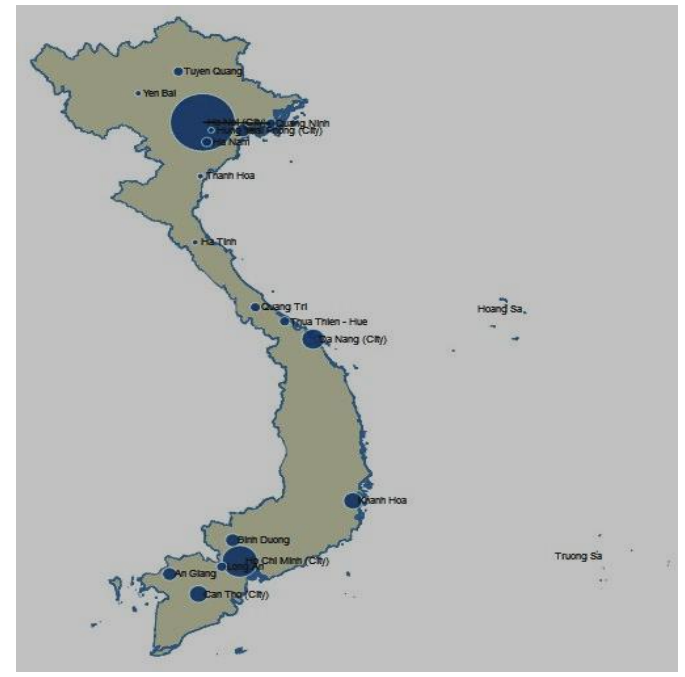

Hình 1. Bản đồ kết quả công bố theo số lương theo địa phương

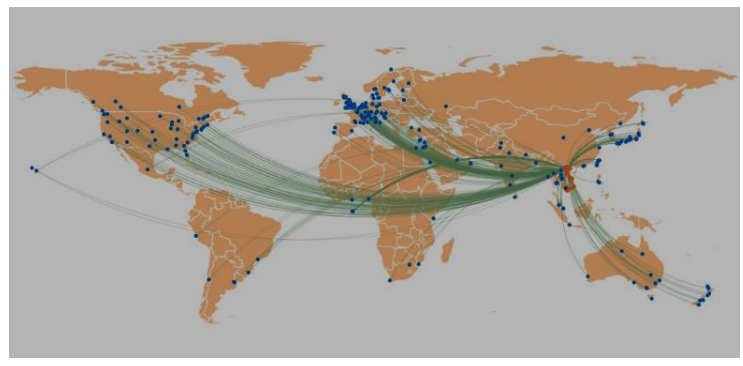

Hình 3. Mức độ hơp tác của các tác giả tù̀ Hà Nội so với các tác giả quốc tế
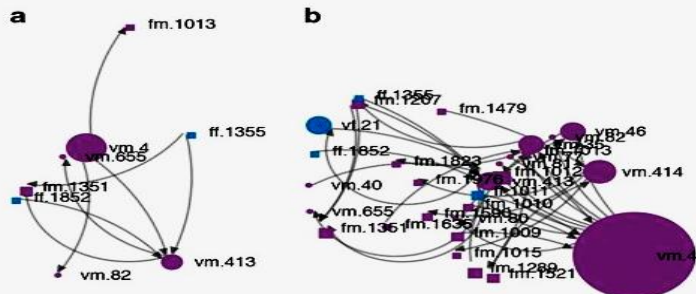

(a) 2008-2010

(b) 2008-2014

Hình 5. Sụ lớn mạnh của một nhóm nghiên cứu trong 3 giai đoạn (Nguồn Vuong et al., 2018 [9])

Từ bảng 4 có thể thấy lĩnh vực kinh tế, y học (chăm sóc sức khoẻ) và giáo dục là ba lĩnh vực có lượng công bố lớn hơn cả. Điều này cho thấy các nghiên cứu ở Việt Nam đang mạnh về các lĩnh vực này.

\subsubsection{Dũ liệu theo nhóm nghiên cưu}

Nhóm nghiên cúu ở đây được chúng tôi định nghĩa là số lượng đồng tác giả xoay quanh một nhà nghiên cứu. Tức là một nhà nghiên cứu nếu ít nhất có công bố chung với một đồng nghiệp, tức là đã tự có cho mình một nhóm nghiên cứu.

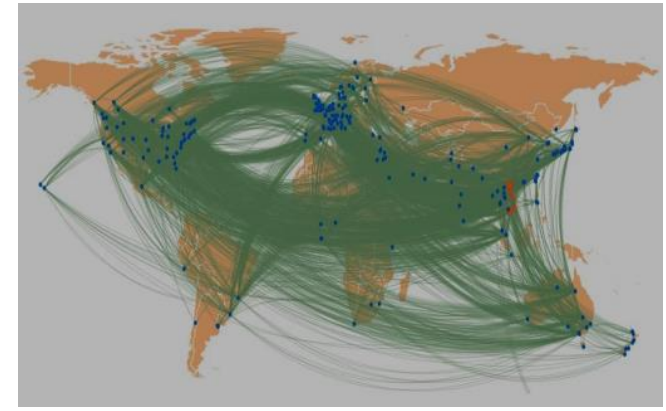

Hình 2. Mức độ hợp tác của các tác giả tù̀ Việt Nam so với các tác giả quốc tế

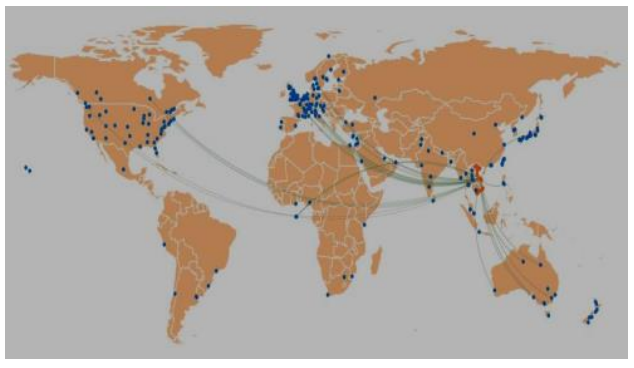

Hình 4. Mức độ hợp tác của các tác giả tù Huế so với các tác giả quốc tế

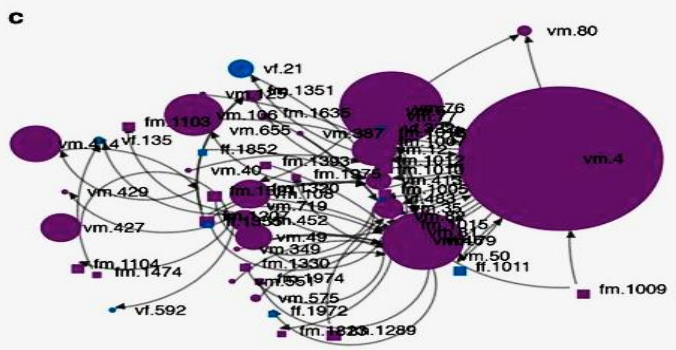

(c) 2008-2018
Dữ liệu NVSS cho thấy, nhóm có đông tác giả nhất là 109 người (nghĩa là có một nhà nghiên cứu đã từng công bố chung ít nhất 01 bài với 108 người trong 11 năm từ 2008-2018).

Xu hướng chung là một nhóm nghiên cứu có kết quả công bố (của toàn nhóm) tốt thì trong nhóm sẽ có một số nhà nghiên cứu có kết quả tốt (chiều ngược lại chưa chắc và sẽ được chúng tôi thảo luận sau). Tất nhiên, từ một nhóm nghiên cứu mạnh với một vài nhà nghiên cứu tốt thì có thể chia thành nhiều nhóm nhỏ. 
Hình 5 (trang trước) mô tả sự lớn mạnh của 1 nhóm nghiên cứu theo 3 giai đoạn : (a) 2008-2010; (b) 2008-2014; và (c) 2008-2018. Sự lớn mạnh này tăng đồng tốc với sự lớn mạnh của 1 cá nhân nhà khoa học có kí hiệu Vm.4. Sự lớn mạnh của cả nhóm mà tác giả $V m$.4 là trưởng nhóm này cũng kèm theo sự lớn mạnh của 1 số nhà khoa học: nếu như giai đoạn 2008-2010, chúng ta thấy có 1 tác giả có kết quả nghiên cứu tương đối cao (vm.413) làm "vệ tinh" quan trọng nhất của Vm.4; thì trong giai đoạn 2008-2014, chúng ta thấy số lượng vệ tinh này lên khoảng 4 người; và trong giai đoạn 2008-2018, số lượng này là khoảng 10 người.

\subsection{Thảo luận}

\subsubsection{Mức độ hội nhập quốc tế của ngành khoa học xã} họi so với ngành khoa học tư nhiên

Kết quả thu thập dữ liệu của chúng tôi tái khẳng định mức độ hội nhập quốc tế của ngành KHXH là thấp hơn so với ngành KHTN. Tổng sản lượng công bố toàn ngành KHXH trong vòng 11 năm chỉ tương đương với tổng sản lượng công bố của một chuyên ngành trong lĩnh vực KHTN trong vòng 2-3 năm. Ví dụ, theo thống kê của Scimago (cũng lấy dữ liệu từ Scopus) thì trong 2 năm 2016 -2017, ngành toán ở Việt Nam công bố 1.857 bài báo; còn trong 3 năm 2015-2017, ngành Khoa học vật liệu ở Việt Nam công bố 2.144 bài báo (Scimago, 2018 [10]); đều là mức tương đương với 1.937 bài báo của toàn ngành $\mathrm{KHXH}$ trong 11 năm 2008-2018.

Mặc dù vậy, nếu nói KHXH Việt Nam không hoặc chưa hội nhập quốc tế thì cũng không thật chính xác. Thậm chí, chuyên ngành Khoa học chính trị, chuyên ngành vốn được xem là "nhạy cảm" thì cũng đã có 67 bài công bố trong 11 năm, chứng tỏ không phải là không có những bộ phận nhất định trong ngành này đã có năng lực hội nhập quốc tế. Bên cạnh đó, số liệu NVSS cũng cho thấy, đã có tới $26,4 \%$ tác giả đã có ít nhất 01 bài solo (tác giả đứng tên một mình) và 40,8\% số bài công bố là hoàn toàn nội lực (không có tác giả không phải là người Việt Nam), điều này cho thấy tiềm năng phát triển và hội nhập của KHXH là rất lớn; nhất là trong bối cảnh các vấn đề nghiên cứu lấy dữ liệu từ Việt Nam vẫn tương đối khan hiếm.

\subsubsection{Vấn đề sản lượng và năng suất}

Tiềm năng phát triển và hội nhập quốc tế của KHXH Việt Nam là tương đối lớn, nhưng vân đề là làm sao khai thác và "chiếm lĩnh" được dư địa đó? Câu hỏi này thực chất đưa chúng ta quay lại một câu hỏi khác, có tính chất căn cốt đối với mọi lĩnh vực (không chỉ là trong nghiên cứu), đó là làm sao để tăng được sản lượng thông qua tăng năng suất?

Để trả lời câu hỏi này, trước tiên ta cùng xem hình 6 và hình 7 dưới đây. Hình 6 cho thấy sản lượng công bố của Việt Nam là tăng tương đối đều trong 11 năm qua; nhưng lại có dấu hiệu đi ngang trong khoảng 3 năm trở lại đây. Nhưng nếu xem xét thêm hình 7 thì ta lại thấy có một vấn đề mới: trong khi số lượng tác giả mới lần đầu tiên có công bố được ghi nhận hàng năm tăng nhanh, thì tổng sản lượng lại có dấu hiệu đi ngang. Điều này hàm ý các tác giả cũ đang có dấu hiệu chững lại? Hay nói cách khác, dường như năng suất của các tác giả cũ đang bị thấp đi?

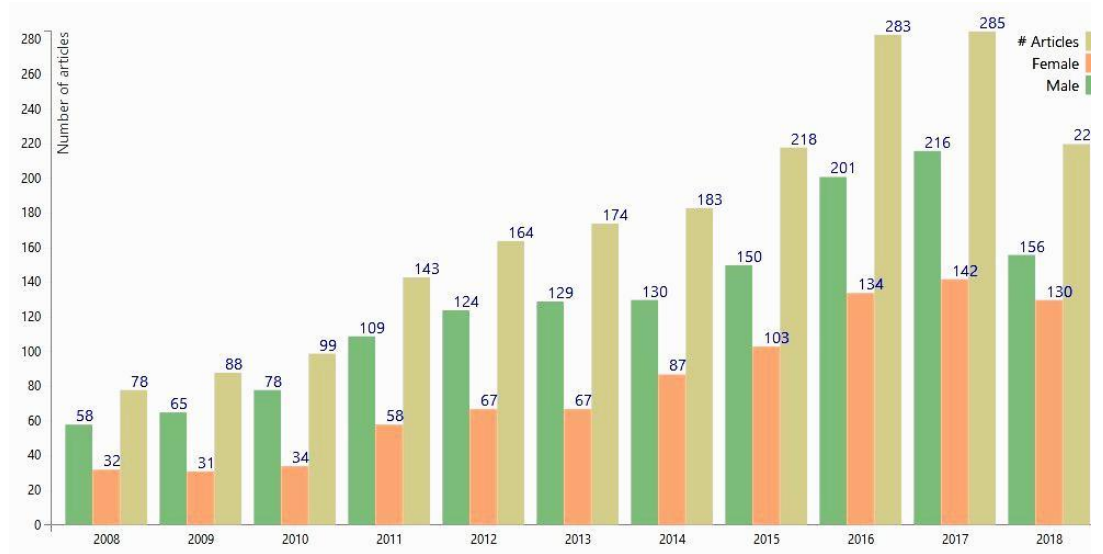

Hình 6. Sản lương công bố của toàn ngành KHXH giai đoạn 2008-2018

(Trục tung là tổng số bài báo; cột bên trái là bài báo có tác giả là nam giới; cột giữa là bài báo có tác giả là nữ giới; cột bên phải là tổng số bài báo)

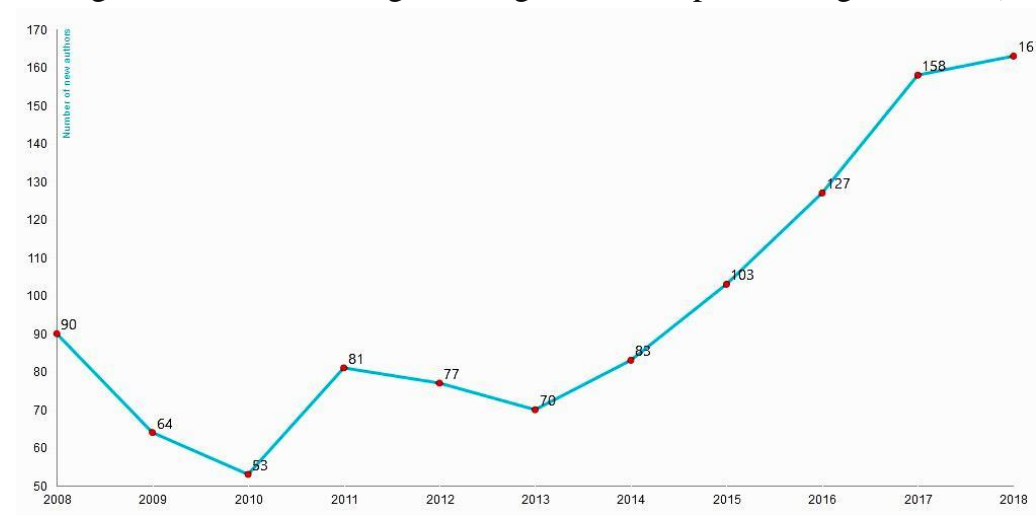

Hình 7. Số lượng tác giả lần đầu có công bố giai đoạn 2008-2018 


\subsubsection{Vấn đề trưởng nhóm nghiên cưu}

Mô tả của chúng tôi về nhóm nghiên cứu do tác giả $\mathrm{Vm} .4$ đứng đầu cho thấy tầm quan trọng của 01 trưởng nhóm nghiên cứu trong việc dẫn dắt nhóm. Tất nhiên, ở chiềungược lại việc có nhóm nghiên cứu cũng giúp chính bản thân trưởng nhóm có thể phát triển lên những tầm cao mới.

Bảng 5a. Top nhà khoa học nam giới người Việt theo số lương bài báo có 01 tác giả công bố giai đoạn 2008-2018

\begin{tabular}{|c|l|c|}
\hline STT & \multicolumn{1}{|c|}{ Mã kí hiệu tác giả } & Số bài \\
\hline 1 & $V m .16$ & 64 \\
\hline 2 & $V m .4$ & 22 \\
\hline 3 & $V m .3$ & 19 \\
\hline 4 & Vm.151 & 18 \\
\hline \multirow{2}{*}{5} & Vm.18 & 11 \\
\hline 7 & $V m .694$ & 11 \\
\hline \multirow{2}{*}{8} & Vm.927 & Vm.75 \\
\cline { 2 - 3 } & Vm.271 & 7 \\
\cline { 2 - 3 } & Vm.342 & 7 \\
\hline
\end{tabular}

Ghi chú: Các tác giả in nghiêng cũng có tên trong bảng $2 \mathrm{a}$ và $2 \mathrm{~b}$ tương ứng.

Mặc dù vậy, dữ liệu của NVSS cho thấy, có một số lượng tương đối lớn nhà khoa học Việt Nam có công bố một mình cao, nhưng lại không có trong danh sách các tác giả có tổng sản lượng cao nhất. Cụ thể, theo thống kê tại bảng $5 \mathrm{a}, 5 \mathrm{~b}$, đối sánh với bảng $2 \mathrm{a}, 2 \mathrm{~b}$, có thể thấy có đến 6 người trong top 10 nhà khoa học nam có nhiều bài một tác giả nhất và 8 người trong top 10 nhà khoa học nũ có nhiều bài một tác giả nhất không xuất hiện trong top 10 người có tổng sản lượng cao nhất tương ứng.

Có 2 cách lí giải cho hiện tượng này: Một là, những nhà khoa học này không thích làm việc theo nhóm; hai là, những nhà khoa học này không có điều kiện để tập hợp nhóm để làm nghiên cứu. Chúng tôi nghiêng về cách lí giải thứ hai và nhiều đồng nghiệp của chúng tôi cũng có quan điểm tương tự. Ví dụ, trả lời phỏng vấn của chúng tôi, Vf.294, nhà khoa học nữ có sản lượng cao nhất (đứng thứ 9 nếu tính chung cả 2 giới), cho rằng: “đến một mức độ phát triển (nghề nghiệp) nào đó, chúng ta không thể không làm mà không có nhóm nghiên cưu".

\section{Kết luận}

Từ những số liệu và phân tích trên, có thể đưa ra một số khuyến nghị cho các nhà hoạch định chính sách, lãnh đạo giáo dục $Đ H$ và khoa học về nghiên cứu về khoa học xã hội.

- Khuyến nghị 1: Hội nhập quốc tế trong nghiên cứu KHXH là xu thế tất yếu, không thể đảo ngược. Trong bối cảnh đó, sử dụng các chỉ mục quốc tế như ISI/Scopus và các chỉ số đo lường khoa học như IF, H-index, Almetrics... là biện pháp hiệu quả nhất giúp đo lường, đánh giá mức độ hội nhập trong nghiên cứu.

- Khuyến nghị 2: Trong các giải pháp nhằm nâng cao sản lượng, chất lượng và năng suất nghiên cứu, việc đầu tư vào các nhóm nghiên cứu mạnh là giải pháp quan

Bảng 5b. Top nhà khoa học nũ giới nguời Việt theo số luợng bài báo có 01 tác giả công bố giai đoạn 2008-2018

\begin{tabular}{|c|c|c|}
\hline STT & Mã kí hiệu tác giả & Số bài \\
\hline 1 & Vf.146 & 7 \\
\hline \multirow{3}{*}{2} & \multirow{3}{*}{$\begin{array}{l}\text { Vf.213 } \\
\text { Vf.275 } \\
\text { Vf. } 470\end{array}$} & 6 \\
\hline & & 6 \\
\hline & & 6 \\
\hline \multirow{6}{*}{5} & \multirow{6}{*}{$\begin{array}{l}\text { Vf.902 } \\
\text { Vf.11 } \\
\text { Vf.99 } \\
\text { Vf.256 } \\
\text { Vf.270 } \\
\text { Vf.294 }\end{array}$} & 5 \\
\hline & & 5 \\
\hline & & 5 \\
\hline & & 5 \\
\hline & & 5 \\
\hline & & 5 \\
\hline
\end{tabular}

trọng, đã được nhiều nghiên cứu trước đây chỉ ra và cũng được nghiên cứu này tái khẳng định.

- Khuyến nghị 3: Trong một nhóm nghiên cứu, người đứng đầu nhóm đóng vai trò quan trọng nhất. Nói cách khác, đầu tư, quan tâm vào nhóm nghiên cứu cũng chính là việc đầu tư, quan tâm đến những người đứng đầu của nhóm - hay nói cách khác là những người có sản lượng, chất lượng, năng suất nghiên cứu tốt.

- Khuyến nghị 4: Mặc dù vậy, căn cứ dữ liệu NVSS như đã trình bày ở trên, có thể thấy, vẫn còn nhiều nhà khoa học có trình độ cao chưa có được nhóm nghiên cứu đủ mạnh để phát huy được tiềm năng. Vì vậy, nhiệm vụ của các nhà hoạch định chính sách và lãnh đạo đại học/khoa học là tạo chính sách, cơ chế để các nhóm nghiên cứu mạnh được hình thành, xoay quanh các nhà khoa học có trình độ cao, thể hiện qua số lượng, chất lượng và sản lượng công bố quốc tế.

- Khuyến nghị 5: Trong các hình thức cấp kinh phí cho nhóm nghiên cứu, chúng tôi cho rằng hình thức khoán chi theo chỉ tiêu công bố (số lượng, chất lượng) là hiệu quả nhất vì hiệu quả và tính dễ giám sát của nó so với các hình thức khác.

- Khuyến nghị 6: Trong khuôn khổ một bài nghiên cứu, chúng tôi chưa thể đưa vào chi tiết các yếu tố có thể có đối với việc đánh giá nhà khoa học/nhóm nghiên cứu, ví dụ như chỉ số $\mathrm{H}, \mathrm{IF}$... Trong các nghiên cứu khác, để đảm bảo các gợi ý toàn diện hơn, chúng tôi khuyến nghị 
các nhà khoa học bổ sung và xem xét các chỉ số kể trên trong quá trình phân tích, đánh giá.

Lời cảm ơn: Nhóm tác giả xin chân thành cảm ơn TS. Vuơng Quân Hoàng, Trung tâm Nghiên cứu Xã hội Liên ngành, Truờng Đại học Phenikaa; Phòng thí nghiệm AI về Dũ liệu xã hội (AI Social Data Lab) và các thành viên thuộc AI Social Data Lab đã góp ý cho bài nghiên cúu này. Nghiên cứu được tài trợ một phần bởi Chwơng trình Khoa học và công nghệ cấp quốc gia giai đoạn 2016-2020 "Nghiên cúu phát triển khoa hoc giáo duc đáp úng yêu cầu đổi mới căn bản, toàn diện nền giáo dục Việt Nam" - Đề tài mã số KHGD/1620.ĐT.032.

\section{Tài liệu tham khảo}

[1] Chính phủ (2003). Nghị định Chính phủ số 122/2003/ND-CP ngày 22/10/2003 về thành lạp Quỹ Phát triển Khoa học và Công nghệ Quốc gia.

[2] Bộ GD-ĐT (2017). Thông tu 08/2017/TT-BGDĐT ngày 4/4/2017 ban hành quy chế tuyển sinh và đào tạo trình đô tiến sĩ.

[3] Vuong, Q.H., La, V.P., Vuong, T.T., Ho, M.T., Nguyen, T.H.K., Nguyen, T.V.H., Pham, H.H., Ho, M.T. (2018). An open database of productivity in Vietnamese social sciences and humanities for public use. Scientific Data, 5: 180188, DOI: 10.1038/sdata.2018.188.

[4] Ho, T. M., Do, T. H., Pham, H. H., \& Vuong, T. T. (2017). Vài quan sát ban đầu tù dũ liệu Scopus về công bố quốc tế trong lĩnh vưc KHXH\&NV của Việt Nam. Tạp chí Kinh tế và Dự báo (http://kinhtevadubao.vn/chi-tiet/91-8323-vai-quan -sat-ban-dau-tu-du-lieu-scopus-ve-cong-bo-quoc-te -trong-linh-vuc-khxhnv-cua-viet-nam.html).

[5] Ho, T. M., Nguyen, H. V., Vuong, T. T., Dam, Q. M., Pham, H. H., \& Vuong, Q. H. (2017). Exploring Vietnamese co-authorship patterns in social sciences with basic network measures of 2008-2017 Scopus data. F1000Research, 6, DOI: https://doi.org/10.12688/f1000research.12404.1.

[6] Ho, T. M., Vuong, T. T., \& Vuong, Q. H. (2017). On the sustainability of co-authoring behaviors in Vietnamese social sciences: A preliminary analysis of network data. Sustainability, 9(11), 2142, DOI: https://doi.org/10.3390/su9112142.

[7] Vuong, Q. H., Ho, T. M., Vuong, T. T., Nguyen, H. V., Napier, N. K., \& Pham, H. H. (2017). Nemo Solus Satis Sapit: Trends of research collaborations in the Vietnamese social sciences, observing 20082017 Scopus data. Publications, 5, 24. DOI:10.3390/publications5040024.
[8] Vuong, Q. H., Napier, N. K., Ho, T. M., Nguyen, V. H., Vuong, T. T., Pham, H. H., \& Nguyen, H. K. T. (2018). Effects of work environment and collaboration on research productivity in Vietnamese social sciences: evidence from 2008 to 2017 scopus data. Studies in Higher Education, 116, DOI: 10.1080/03075079.2018.1479845.

[9] Vuong, T. T., Nguyen, H., Ho, T., Ho, T., \& Vuong, Q. H. (2018). The (in) significance of sociodemographic factors as possible determinants of Vietnamese social scientists' contribution-adjusted productivity: Preliminary results from 2008-2017 Scopus data. Societies, 8(1), 3, DOI:10.3390/ soc8010003.

[10] Scimago. (2018). Country Rankings. Retrieved from: https://www.scimagojr.com/countryrank.php.

\section{THỰC TRẠNG CÔNG TÁC PHÂN LUỒNG...}

(Tiếp theo trang 10)

\section{Tài liệu tham khảo}

[1] Bộ Chính trị (2011). Chỉ thị số 10-CT-TW ngày 5/12/2011 về phổ câp giáo dục mầm non cho trẻ 5 tuổi, củng cố kết quả phổ cập giáo duc tiểu học và trung học co sở, tăng cường phân luồng học sinh sau trung hoc cơ sở và xóa mù chũ cho nguoòi lón.

[2] Ban Chấp hành Trung ương (2013). Nghi quyết số 29-NQ/TW ngày 04/11/2013 về đổi mới căn bản, toàn diện giáo duc và đào tạo, đáp úng yêu cầu công nghiệp hóa, hiện đại hóa trong điều kiện kinh tế thi truờng định hướng xã hội chủ nghĩa và hội nhập quốc tế.

[3] Đỗ Thị Bích Loan (2012). Phân luồng và liên thông trong hệ thống giáo duc - Huớng đến xã hội học tập. Ki yếu Hội thảo quốc tế "Hướng tới đổi mới nền giáo dục Việt Nam”. Hà Nội, tháng 10/2012, tr 111-117.

[4] Trần Cồng Phong - Đỗ Thị BíchLoan (2016). Phân luồng và liên thông trong hệ thống giáo duc quốc dân Việt Nam - Lí luận và thưc tiễn. NXB Giáo dục Việt Nam.

[5] Sở GD-ĐT Lạng Sơn (2018). Báo cáo số 1290/BCSGDĐT, ngày 14/06/2018 về công tác phân luồng sau giáo duc trung học cơ sở tại vùng đồng bào dân tộc thiểu số.

[6] Thủ tướng Chính phủ (2018). Quyết đinh số 522/QĐ-TTg phê duyệt dề án "Giáo duc huớng nghiẹp và định hướng phân luồng học sinh trong giáo duc phổ thông giai đoạn 2018-2025".

[7] Ủy ban nhân dân tỉnh Lạng Sơn (2019). Báo cáo 123/BC-UBND, ngày 27/03/2019 về tình hình thưc hiện các chương trình, chính sách liên quan đến công tác phân luồng sau giáo duc trung học co sở tại các vùng đồng bào dân tộc thiểu số giai đoạn 2010-2018. 